\title{
Validation of the Wind-US Unstructured Flow Solver for Wall-Bounded Flows
}

\author{
Vance Dippold, III \\ NASA Glenn Research Center, Cleveland, OH 44135 \\ and \\ Stanley R. Mohler, Jr. ${ }^{\dagger}$ \\ QSS Group, Inc., Cleveland, OH 44135
}

\begin{abstract}
The Wind-US computational fluid dynamics flow solver was validated for incompressible and supersonic flows over a flat plate and a backward-facing step. The calculations used unstructured hexahedral grids. The solutions were compared to experimental data as well as solutions obtained with the Wind-US structured flow solver. The unstructured solver solutions exhibited small differences from the structured solver solutions, but still showed overall good agreement with the experimental data.
\end{abstract}

\section{Nomenclature}

$C_{f} \quad=$ skin friction coefficient

$C_{p} \quad=$ pressure coefficient

$H \quad=$ step height

$M \quad=$ Mach number

$p \quad=$ static pressure

$p_{\text {ref }} \quad=$ reference pressure

$\operatorname{Re}_{x} \quad=$ flat plate Reynolds number based on distance from leading edge

$U_{e} \quad=$ edge velocity

$U_{\text {inf }} \quad=$ freestream velocity

$U_{\text {ref }} \quad=$ reference velocity in duct flow

$u=$ axial component of velocity

$u^{+} \quad=$ dimensionless velocity; $u^{+}=\left(\frac{1}{u}\right) \cdot \sqrt{\frac{\tau_{w}}{\rho_{w}}}$

$x, y=$ axial and transverse coordinates

$y^{+} \quad=$ dimensionless transverse coordinate; $y^{+}=\left(\frac{y \cdot \rho_{w}}{\mu_{w}}\right) \cdot \sqrt{\frac{\tau_{w}}{\rho_{w}}}$

$\delta=\quad$ boundary layer thickness; defined as the location where $u=0.99 U_{e}$

$\delta^{*} \quad=$ boundary layer displacement thickness

$\theta=$ boundary layer momentum thickness

$\mu_{w} \quad=$ dynamic viscosity at the wall

$\rho_{e} \quad=$ density at boundary layer edge

$\rho_{w} \quad=$ density at the wall

$\tau_{w} \quad=$ wall shear stress

* Aerospace Engineer, Inlet and Nozzle Branch, 21000 Brookpark Rd, M.S. 86-7, Member AIAA.

+ Aerospace Engineer, Aerodynamics, Combustion and Icing Section, 21000 Brookpark Rd., Member AIAA. 


\section{Introduction}

The NPARC Alliance has recently added an unstructured flow solver ${ }^{1}$ to its WIND structured flow solver. With this new capability, WIND has been renamed Wind-US. Wind-US can solve flows on structured, unstructured, or hybrid grids (consisting of both structured and unstructured zones). The unstructured solver allows grids consisting of a mixture of completely general types of cells, including tetrahedral, hexahedral, prismatic, and pyramidal. Mohler ${ }^{2,3}$ has recently documented a complete WindUS solution process using tetrahedral, pyramidal, and prismatic cells.

The NPARC Alliance maintains an archive of Wind-US CFD cases, complete with input files, on its Verification and Validation Web Site ${ }^{4}$. The site is dominated by cases for the structured flow solver in Wind-US. To address the need for validating the unstructured flow solver, the current study presents flow solutions for two classes of wall-bounded flows: flow over a flat plate and flow over a rearwardfacing step. The cases test the ability of Wind-US to predict turbulent boundary layers with no pressure gradient and separating flow with adverse pressure gradient in compressible and incompressible flow conditions.

The purpose of this study is to test the performance of the Wind-US unstructured solver using four benchmark wall-bounded flows. The results from the unstructured solver will be compared to experimental results and results from the Wind-US structured solver.

\section{Validation Cases}

This study uses four benchmark flows: incompressible flows over a flat plate and a rearwardfacing step and supersonic flows over a flat plate and rearward-facing step. These flows were chosen because they tested the ability of Wind-US to predict turbulent boundary layer growth and flow separation and reattachment. A description of each of the four test flows is given below.

\section{A. Incompressible Flow Over a Flat Plate}

An incompressible flow over a flat plate with a fully-developed turbulent boundary layer was run using the Wind code. This flat plate flow has been documented by Wieghardt ${ }^{5}$, Coles, et al ${ }^{6}$, and Patel, et $\mathrm{al}^{7}$. More recently, turbulence model validation studies using this benchmark flow were conducted by Yoder and Georgiadis ${ }^{8}$ and also by Dippold ${ }^{9}$. These analyses simulated Mach 0.2 flow over a $16.67 \mathrm{ft}$ long flat plate. The domain included a $1.0 \mathrm{ft}$ section before the leading edge of the plate to set up the flow. In Wind-US, the total pressure and total temperature of the flow were set at $14.7 \mathrm{lb} / \mathrm{in}^{2}$ and $530^{\circ} \mathrm{R}$, respectively.

\section{B. Supersonic Flow Over a Flat Plate}

Coles ${ }^{10,11,12}$ conducted experiments for turbulent boundary layers with supersonic freestream flow over a flat plate. Tests were conducted in the 20 inch Supersonic Wind Tunnel at the Jet Propulsion $\mathrm{Lab}$ at Mach numbers ranging from 1.3 to 4.5 and Reynolds numbers ranging from $2^{*} 10^{5}$ to $9^{*} 10^{6}$. The flat plate was 33 inches long and spanned the entire test section width. To hasten turbulent transition and produce a fully-developed turbulent boundary layer, Coles tripped the boundary layer using sand paper, fences, and air jets. This study simulated the test with a Mach 4.5 freestream flow.

\section{Incompressible Flow Over a Rearward-Facing Step}

Incompressible turbulent flow over a rearward-facing step was investigated by Driver and Seegmiller ${ }^{13}$. Figure 1 shows a schematic of this flow. The test rig used a 39.4 in long, 5.94 in wide, and 3.98 in high rectangular inflow duct that was followed by a 0.50 in high rearward-facing step. The wall opposite the step was hinged 0.236 in upstream of the step. This hinged wall could then be angled to introduce a pressure gradient to the freestream region of the flow, downstream of the step. In the studies presented here, the zero angle configuration is simulated. The inlet flow leading to the rearward-facing step had a freestream Mach number of 0.128 at a location four step heights upstream of the step. Freestream total pressure and temperature were set to atmospheric conditions. 


\section{Supersonic Flow Over a Rearward-Facing Step}

Smith ${ }^{14}$ performed a number of tests to measure heat transfer and turbulent transition in supersonic flow over a rearward-facing step. Additionally, Smith observed the structure of the expansion fan off the edge of the step and the oblique shock wave that forms where the flow reattaches downstream of the step. The model and flow features are pictured in Figure 2. The model was water-cooled and had a moveable wall such that the step height could be set at 0 in, 0.443 in, or $0.75 \mathrm{in}$. Smith examined flows with freestream Mach numbers ranging from 2.5 to 5.0 and Reynolds numbers, based on the entrance flow length, ranging from $2.5^{*} 10^{5}$ to $1.8^{*} 10^{6}$. The low Reynolds number allowed the flow to remain laminar and the boundary layer to remain relatively small until after the flow separated as it passed over the rearward-facing step. Transition to turbulent flow took place over the separated region. This paper looks at a Mach number 2.5 flow over the 0.443 in backstep. The freestream Reynolds number for this case was $4.6^{*} 10^{5} \mathrm{in}^{-1}$.

\section{Computational Method}

\section{A. Flow Solver}

This study utilized Wind-US version 1.01,15,16. Wind-US is a general Reynolds-Averaged Navier Stokes (RANS) code, developed and managed by the NPARC Alliance. The NPARC Alliance is a partnership among NASA Glenn Research Center, USAF Arnold Engineering Development Center, and The Boeing Company. Wind-US incorporates the Wind code - a multi-zone, structured grid, compressible flow solver - with a new unstructured flow solver. The structured solver offers the user a wide choice of turbulence models: several zero-equation models, Spalart-Allmaras ${ }^{17}$ and other singleequation models, and the Chien $\mathrm{K}-\varepsilon^{18}$ and Menter SST ${ }^{19}$ two-equation models. The unstructured solver in the production version of Wind-US is currently limited to using only the Spalart-Allmaras and Goldberg pointwise turbulence models. Wall functions are also available for use within Wind-US. Wind-US also has the ability to use both structured and unstructured solvers on different zones of the same grid.

While the unstructured solver of Wind-US uses many of the same features and options as the structured solver, there are several noteworthy differences. In many cases, it is necessary to use some level of smoothing in order to obtain a solution with the unstructured solver. Mohler ${ }^{2,3}$ discusses the effect of smoothing inputs on the solution. A second difference is that the unstructured solver can use a Rusanov differencing scheme as well as a Roe differencing scheme, which is the default for the structured solver. The Wind-US User's Guide ${ }^{16}$ recommends using the Rusanov differencing scheme, especially for flows with Mach numbers exceeding 2.5.

\section{B. Computational Procedures}

All the analyses were performed on an Intel Xeon-based workstation running the Linux operating system. Run times ranged from several hours for the flat plate and supersonic back step to nearly a day for the incompressible back step.

To ensure that the flow solution had converged, various flow quantities were monitored in addition to the $\mathrm{L}^{2}$ residual. For the flat plate cases, the convergence of skin friction along the plate and the velocity profile at an arbitrary station were observed. Mass flow and skin friction were monitored in the rearward-facing step cases. The solution was deemed converged when these quantities did not change noticeably over the course of several hundred iterations.

\section{Computational Grids}

The unstructured solver within Wind-US requires 3D grids, consisting of two or more elements in the normal direction. The Wind-US structured solver can use either 2D or 3D grids. Structured 2D grids were created for each flow case. Then, the 2D grids were extruded in the normal direction to 3D grids and converted to unstructured format. Therefore, the unstructured grids used 3D grid topology equivalent to the $2 \mathrm{D}$ structured grids. 


\section{Incompressible Flow Over a Flat Plate}

The grid for the incompressible flat plate flow consisted of a single zone. The 2D grid size was $111 \times 81$ points and the $3 \mathrm{D}$ grid was $111 \times 81 \times 3$ points. The grid was packed to the wall surface with a first grid point spacing corresponding to an average $y^{+}=2$.

2. Supersonic Flow Over a Flat Plate

The grid for the supersonic flow over a flat plate also consisted of a single zone. The 2D grid size was $46 \times 81$ points, and the 3D grid consisted of $46 \times 81 \times 3$ points. Two first grid point spacings were used when packing points at the wall: $y^{+}=1.0$ and $y^{+}=0.1$.

3. Incompressible Flow Over a Rearward-Facing Step

For the incompressible flow over a rearward-facing step, the flow domain was divided into two zones. The first zone modeled the flow from the inflow to the edge of the step and the second zone modeled the flow from the step to the outflow, as shown in Figure 3. For the 2D grid, the first zone consisted of 101x131 grids points and the second zone consisted of 138x185 grid points. Similar to the flat plate grids, the 2D grid was extruded to three points in the normal direction for the 3D grid. Additionally, the grid points were packed to the walls with a nominal wall spacing of $y^{+}=1$.

4. Supersonic Flow Over a Rearward-Facing Step

The grid for the supersonic flow over a rearward-facing step also consisted of two zones. For the 2D grid, the first zone measured 41x61 grid points and the second zone measured 101x101 grid points. The 3D grid extruded the 2D grid to three points in the normal direction. Grid points were packed to the walls with a first grid point spacing of $y^{+}=1$.

\section{Results}

The results of the Wind-US analyses for each test case are presented below. An extra step was required to post-process the unstructured solutions: a CFPOST rake file was created using the structured grid, and the unstructured solution was interpolated onto this rake file. Once this was performed, velocities, pressures, and shear stress could be examined at arbitrary points selected by the user.

\section{A. Incompressible Flow Over a Flat Plate}

Four analyses of incompressible flow over a flat plate were run using the Wind-US code. Two structured analyses were run using two different boundary conditions on the grid boundary opposite the flat plate: the first using the freestream boundary condition; the second using the inviscid wall boundary condition. While the freestream boundary condition is more appropriate, use of the inviscid boundary condition was necessary because the freestream boundary condition in the Wind-US unstructured solver was found to not work properly. When an unstructured grid analysis was run using the freestream boundary condition, the flow was found to accelerate substantially as is moved across the flat plate. It was not until the inviscid boundary condition was used instead that this unphysical event ceased. The freestream boundary condition for the unstructured solver will be corrected in a future release of the Wind-US code. Two analyses were run using the Wind-US unstructured solver: one using a secondorder Rusanov cell-centered differencing scheme; the other using a second-order Roe cell-center scheme. The structured grid analyses use a second-order Roe upwind-biased differencing scheme, which is the default scheme.

Figure 4 shows the skin friction plotted as a function of the Reynolds number, where

$$
C_{f}=\frac{\tau_{w}}{\frac{1}{2} \cdot \rho_{e} \cdot U_{e}^{2}}
$$

and

$$
\operatorname{Re}_{x}=\frac{\rho_{\infty} \cdot U_{\infty} \cdot x}{\mu_{\infty}}
$$

The wall shear stress, $\tau_{w}$, is defined as:

$$
\tau_{w}=\left.\left.\mu_{w} \cdot \frac{d u}{d y}\right|_{w} \approx \mu_{w} \cdot \frac{\Delta u}{\Delta y}\right|_{w}
$$


The structured grid solutions, in Figure 4, show excellent agreement with the experimental data. It is also important to note that the upper boundary of the computational domain is sufficiently far enough away from the wall that there is a negligible difference between using the freestream boundary condition or the inviscid wall boundary condition. The unstructured grid solutions predicted the skin friction to be about $7 \%$ higher than the experimental data across the entire flat plate. However, there is little difference between the Roe scheme and the Runsanov scheme for this case.

The velocity profile through the boundary layer at $R e_{x}=1.03^{*} 10^{7}$ is plotted in Figure 5 using the non-dimensionalized variables $y^{+}$and $u^{+}$. Like the skin friction plot, the structured grid solutions show excellent agreement with the experimental data while the unstructured solutions differ from the experimental data by about $4 \%$. Table 1 lists the boundary layer thickness, $\delta$, momentum thickness, $\theta$, and displacement thickness, $\delta^{*}$, for the Wind-US solutions at $R e_{x}=1.03^{*} 10^{7}$. The momentum thickness and displacement thickness are defined as:

$$
\begin{gathered}
\theta=\left(\frac{1}{\rho_{e} \cdot U_{e}}\right) \cdot \int_{0}^{\delta}(\rho \cdot u) \cdot d y-\left(\frac{1}{\rho_{e} \cdot U_{e}^{2}}\right) \cdot \int_{0}^{\delta}\left(\rho \cdot u^{2}\right) \cdot d y \\
\delta^{*}=\int_{0}^{\delta} d y-\left(\frac{1}{\rho_{e} \cdot U_{e}}\right) \cdot \int_{0}^{\delta}(\rho \cdot u) \cdot d y
\end{gathered}
$$

While no experimental data for the boundary layer thickness is available, the Wind-US solution data is compared to the correlation by Schlichting 20 for $\mathrm{a}^{1 /} / 7^{-}$th power velocity distribution:

$$
\begin{gathered}
\frac{\delta}{x}=0.37 \cdot R e_{x}^{-0.2} \\
\theta=\frac{7}{72} \cdot \delta \\
\delta^{*}=\frac{1}{8} \cdot \delta
\end{gathered}
$$

For each of the integrated boundary layer quantities, the Wind-US predictions are all $9-11 \%$ lower than what is predicted using Schlichting's formulations. The unstructured solutions show good agreement with the structured solutions, differing by less than $2 \%$ for $\delta$ and less than $10 \%$ for $\theta$ and $\delta^{*}$.

Table 1: Integrated boundary layer quantities for incompressible flow over a flat plate

\begin{tabular}{|l|c|c|c|}
\multicolumn{1}{|c|}{ Case } & $\boldsymbol{\delta} \boldsymbol{e}_{\boldsymbol{x}}=\mathbf{1 . 0 3} \mathbf{1}^{*} \mathbf{1 0}^{\mathbf{7}}$. \\
\hline Schlichting Correlation & 1.31 & $\boldsymbol{\theta}$ [in] & $\boldsymbol{\delta}^{*}$ [in] \\
\hline $\begin{array}{l}\text { Wind-US, Structured grid, } \\
\text { Freestream BC, Roe }\end{array}$ & 1.22 & 0.127 & 0.164 \\
\hline $\begin{array}{l}\text { Wind-US, Structured grid, } \\
\text { Inviscid wall BC, Roe }\end{array}$ & 1.22 & 0.113 & 0.149 \\
\hline $\begin{array}{l}\text { Wind-US, Unstructured grid, } \\
\text { Inviscid wall BC, Rusanov }\end{array}$ & 1.23 & 0.121 & 0.149 \\
\hline $\begin{array}{l}\text { Wind-US, Unstructured grid, } \\
\text { Inviscid wall BC, Roe }\end{array}$ & 1.19 & 0.115 & 0.153 \\
\hline
\end{tabular}

\section{B. Supersonic Flow Over a Flat Plate}

Four analyses of Mach 4.5 turbulent flow over a flat plate were run with Wind-US. Two cases used structured grids with first point grid spacings of $y^{+}=1.0$ and $y^{+}=0.1$, and two cases used unstructured grids with first point grid spacings of $y^{+}=1.0$ and $y^{+}=0.1$. Figure 6 shows the skin friction plotted as a function of the Reynolds number for the four Wind-US analyses and several experimental data sets. In the experiment, a number of different methods were used to transition the flow to turbulent: a natural transition, a fence trip, a sand trip, and air jets. The CFD analyses compare well with all the data, and most accurately with the "tripped" flow experimental data. This is expected as the CFD analyses were run fully turbulent. The structured grid analysis and the unstructured grid analysis with wall spacing of 
$y^{+}=1.0$ show excellent agreement with each other. For the unstructured grid with wall spacing of $y^{+}=0.1$, the Wind-US unstructured solver predicts skin friction to be about 10\% higher than the other analyses. Figure 7 shows the velocity profiles through the boundary layer at $R e_{x}=3.81^{*} 10^{6}$. All four Wind-US analyses show excellent agreement with each other and excellent agreement with "tripped" flow experimental data.

Figures 8a-8c compare the boundary layer thickness, $\delta$, momentum thickness, $\theta$, and displacement thickness, $\delta^{*}$, of the experimental data sets and Wind-US analyses at $R e_{x}=3.81^{*} 10^{6}$. There is a significant difference between the integrated boundary layer quantities of the "tripped" flow data sets and the natural transition data set - on the order of $50 \%$. Of the "tripped" flow data sets, the fence trip consistently results in a thicker boundary layer than the sand and air jet trips. The boundary layer thickness predicted by the unstructured grid solutions is on the order of $10 \%$ less than that predicted by the structured grid solutions. But, all the CFD solutions fall in the middle of the "tripped" flow experimental data sets. Similarly for the momentum thickness, the unstructured grid solutions prediction is about $15 \%$ smaller than that of the structured grid solutions, yet all the CFD solutions are in the range of the "tripped" flow experimental results. The Wind-US solutions' predictions of the displacement thickness show excellent agreement with each other, and show good agreement with the sand and air jet "tripped" flow data.

\section{Incompressible Flow Over a Rearward-Facing Step}

The Mach 0.128 flow over a rearward-facing step tests the ability of Wind-US to predict the effects of flow separation and reattachment. As mentioned previously, the unstructured grid solver within Wind-US is currently limited to using only the Spalart-Allmaras ${ }^{17}$ and Goldberg pointwise turbulence models. Dalbello, et $\mathrm{al}^{21}$ have shown that Menter's SST turbulence model ${ }^{19}$ performs the best in the presence of separated flows. Therefore, an additional structured grid case, using the SST turbulence model, was run to better ascertain the performance of the Wind-US structured and unstructured grid solvers versus the performance of the turbulence model when compared to experimental data.

The skin friction for the flow over a backstep is plotted in Figure 9. The axial coordinate is normalized by the step height, $H=0.5 \mathrm{in}$. All the Wind-US analyses do a good job of predicting separation and reattachment. In fact, the CFD solutions all show excellent agreement with the experimental data regarding the location of reattachment. This is further shown in Table 2. In Figure 9, the structured grid analysis with the SST model shows the closest agreement with the experimental data, predicting a slightly lower skin friction in the separated region. This actually corresponds to a higher shear in the reverse flow direction. The structured grid analyses with the Spalart-Allmaras model predicts lower skin friction in the separated region, too, and also gives lower values of skin friction downstream of where the flow reattaches. The three structured grid solutions show good agreement with each other upstream of the step, but predict a value of skin friction higher than what was observed experimentally. The unstructured grid analyses (using only the Spalart-Allmaras turbulence model) show an even higher value of skin friction than the structured grid solutions upstream of the step. After the step, the Roe scheme solution shows the best agreement with the experimental date after the flow reattaches.

Table 2: Location of flow reattachment for Mach 0.128 flow over a rearward-facing step.

\begin{tabular}{|l|c|}
\hline \multicolumn{1}{|c|}{ Case } & $(x / H)_{\text {reattach }}$ \\
\hline Driver Experiment & 6.28 \\
\hline Wind-US, 2D Structured Grid, SST, Roe & 6.42 \\
\hline Wind-US, 2D Structured Grid, S-A, Roe & 6.14 \\
\hline Wind-US, 3D Structured Grid, S-A, Roe & 6.14 \\
\hline Wind-US, 3D Unstructured Grid, S-A, Rusanov & 5.70 \\
\hline Wind-US, 3D Unstructured Grid, S-A, Roe & 6.01 \\
\hline
\end{tabular}


The pressure coefficient along the wall surface is plotted in Figure 10. The pressure coefficient is defined by:

$$
C_{p}=\frac{p-p_{\infty}}{\frac{1}{2} \cdot \rho_{\infty} \cdot U_{\infty}^{2}}
$$

The structured and unstructured grid solutions using the Spalart-Allmaras turbulence model show excellent agreement with each other and reasonably good agreement with the experimental data. The analyses predict the pressure low through the separated region and the pressure high downstream of reattachment. The structured grid solution with the SST model does a better job predicting the correct pressure through the separated region, yet also suffers from predicting too high pressure downstream of reattachment.

Velocity profiles of the flow over the backstep are plotted in Figure 11. The velocities are normalized by reference velocity, $U_{r e f}$, which in this case is an area-averaged velocity $4 H$ upstream of the step. Wind-US analyses show very good agreement with each other and the experimental data. The only region in which the CFD-predicted velocities show any disagreement with the experimental data is inside the separated region of the flow and just downstream reattachment. With regards to the velocity profiles, the SST turbulence model shows better agreement with the experimental data immediately following the step. Farther downstream and near the point of reattachment, the Spalart-Allmaras model gives the better prediction. There is little difference between structured and unstructured grid solutions or between Roe and Rusanov scheme solutions.

\section{Supersonic Flow Over a Rearward-Facing Step}

An extra supersonic rearward-facing step analysis was performed using Menter's SST turbulence model, as also done with the incompressible rearward-facing step. Figure 12 shows a plot of the pressure along the surface. The $x$-coordinate is normalized by the step height, $H=0.443$ in in this case. Following the convention of Smith ${ }^{14}$, the local surface pressure is normalized by the pressure along the surface at $x / H=-3.39$. All the Wind-US solutions show excellent agreement with each other. The Wind-US solutions also show good agreement with the experimental data. The CFD solutions predict lower pressures immediately following the step than observed experimentally and a slower pressure recovery in the region of $x / H=3$ to $x / H=5$. The unstructured grid solutions show excellent agreement with the structured grid solutions.

Figure 13 shows the contour plots of the Mach number and the normalized static pressure for Mach 2.5 flow over a rearward-facing step. The unstructured grid using the Rusanov scheme solution is shown, but all the cases look relatively the same. The expansion over the corner, the region of separated flow on the base of the step, and the reattachment shock are all clearly visible. Table 3 lists the reattachment points for each Wind-US solution. Although there is no experimental data to compare to, this is a good indicator of how consistent the solutions are with each other. The structured grid solution using the Spalart-Allmaras turbulence model predicts reattachment at $2.53 \mathrm{H}$ downstream of the step. The structured grid solution with the SST turbulence model, which has demonstrated better performance when separation is present ${ }^{20}$, predicts an earlier reattachment at $2.29 \mathrm{H}$ downstream of the step. The unstructured grid solutions predict a significantly earlier reattachment: $2.00 \mathrm{H}$ for the Roe scheme and $1.89 H$ for the Rusanov scheme.

Table 3: Reattachment locations for Mach 2.5 flow over a rearward-facing step.

\begin{tabular}{|l|c|}
\hline \multicolumn{1}{|c|}{ Case } & $(x / H)_{\text {reattach }}$ \\
\hline Smith Experiment & $\mathrm{n} / \mathrm{a}$ \\
\hline Wind-US, 2D Structured Grid, SST, Roe & 2.29 \\
\hline Wind-US, 2D Structured Grid, S-A, Roe & 2.53 \\
\hline Wind-US, 3D Structured Grid, S-A, Roe & 2.53 \\
\hline Wind-US, 3D Unstructured Grid, S-A, Rusanov & 1.89 \\
\hline Wind-US, 3D Unstructured Grid, S-A, Roe & 2.00 \\
\hline
\end{tabular}




\section{Conclusions}

The goal of this study was to ascertain the performance of the Wind-US unstructured grid solver for several benchmark wall-bounded flows. For incompressible flows, the Wind-US unstructured solver tends to predict wall shear stress values higher than the structured solver. In supersonic flows, the Wind-US unstructured solver solutions demonstrated excellent consistency with the structured solver solutions. In separated flows, the unstructured solver predicts reattachment earlier than the structured solver. The Rusanov scheme is the recommended differencing scheme with unstructured grids ${ }^{16}$, especially for high speed flows. However, the differences between the Rusanov and Roe schemes were small and neither scheme proved to be clearly better than the other, including solution stability. It must also be noted that the Wind-US unstructured solver runs slower than the structured solver, requiring about $65 \%$ more clock time than an equivalent structured grid. The real advantages of unstructured grids is that they can be used to model flows around complex or irregularly shaped objects, and they should help reduce the number of grid points in regions away from surfaces. This study has demonstrated that the cost in solution fidelity of using unstructured grids in these situations is relatively small.

\section{Acknowledgments}

This work was supported by the Quiet Aircraft Technology project. The authors also wish to thank Dr. Nicholas Georgiadis and Dr. Dennis Yoder for all their illuminating insights and thoughtful advice.

\section{References}

1 Mani, M., Cary, A., Ramakrishnan, S. V., "A Structured and Hybrid-unstructured Grid Euler and Navier-Stokes Solver for General Geometry," AIAA Paper 2004-0524, Jan. 2004.

2 Mohler, S. R., "Wind-US Flow Calculations for the M2129 S-Duct Using Structured and Unstructured Grids," NASA CR-2003-212736, AIAA Paper 2004-0525, Jan. 2004.

${ }^{3}$ Mohler, S. R., "Wind-US Unstructured Flow Solutions for a Transonic Diffuser," AIAA Paper 2005-1004, January 10-13, 2005.

${ }^{4}$ NPARC Alliance CFD Verification \& Validation Web Site,

http://www.grc.nasa.gov/WWW/wind/valid/

${ }^{5}$ Wieghardt, K. and Tillman, W., "On the Turbulent Friction Layer for Rising Pressure," NACA TM-1314, 1951.

${ }^{6}$ Coles, D. E., and Hirst, E. A., editors, Computation of Turbulent Boundary Layers - 1968 AFOSR-IFPStanford Conference, Vol. 2, Stanford University, CA, 1969.

7 Patel, V. C., Rodi, W., and Scheuerer, G., "Turbulence Models for Near-Wall and Low-Reynolds Number Flows: A Review," AIAA Journal, Vol. 23, No. 9, Sept. 1985, pp. 1308-1319.

8 Yoder, D. A., and Georgiadis, N. J., "Implementation and Validation of the Chien k-epsilon Turbulence Model in the WIND Navier-Stokes Code," AIAA Paper 99-0745, Jan. 1999.

9 Dippold, V., "Investigation of Wall Function and Turbulence Model Performance within the Wind Code," AIAA Paper 2005-1002, Jan. 2005.

${ }^{10}$ Coles, D., "Measurements in the Boundary Layer on a Smooth Flat Plate in Supersonic Flow: I.

The Problem of the Turbulent Boundary Layer," Jet Propulsion Laboratory Report No. 20-69, June 1953.

${ }^{11}$ Coles, D., "Measurements in the Boundary Layer on a Smooth Flat Plate in Supersonic Flow: II.

Instrumentation and Experimental Techniques at the Jet Propulsion Laboratory," Jet Propulsion Laboratory Report No. 20-70, June 1953.

${ }^{12}$ Coles, D., "Measurements in the Boundary Layer on a Smooth Flat Plate in Supersonic Flow: III. Measurements in a Flat-Plate Boundary Layer at the Jet Propulsion Laboratory," Jet Propulsion Laboratory Report No. 20-71, June 1953.

${ }^{13}$ Driver, D. M. and Seegmiller, H. L., "Features of a Reattaching Turbulent Shear Layer in Divergent Channel Flow," AIAA Journal, Vol. 23, No. 2, Feb. 1985, pp. 163-171.

${ }^{14}$ Smith, H. E., "The Flow Field and Heat Transfer Downstream of a Rearward Facing Step in Supersonic Flow," ARL 67-0056, March 1967. 
${ }^{15}$ Nelson, C. C. \& Power, G. D., “CHSSI Project CFD-7: The NPARC Alliance Flow Simulation System," AIAA Paper 2001-0594, 2001.

${ }^{16}$ The Wind User's Guide, User Manual, The NPARC Alliance,

http://www.grc.nasa.gov/WWW/winddocs/user/index.html

${ }^{17}$ Spalart, P. R. \& Allmaras, S. R., "A One-Equation Turbulence Model for Aerodynamic Flows," AIAA Paper 1992-0439, 1992.

${ }^{18}$ Chien K. Y., "Predictions of Channel and Boundary layer Flows with a Low-Reynolds-Number Turbulence Model," AIAA Journal, Vol. 20, No. 1, pp. 33-38, 1982.

${ }^{19}$ Menter, F. R., "Two-Equation Eddy Viscosity Turbulence Models for Engineering Applications," AIAA Journal, Vol. 32, No. 8, pp. 1598-1605, 1994.

${ }^{20}$ Schlichting, H., Boundary-Layer Theory, McGraw-Hill, New York, 1942; 7th ed, 1979.

${ }^{21}$ Dalbello, T., Dippold, V., and Georgiadis, N., "Computational Study of Separating Flow in a Planar Subsonic Diffuser," NASA TM-2005-213894, October, 2005. 


\section{Figures}

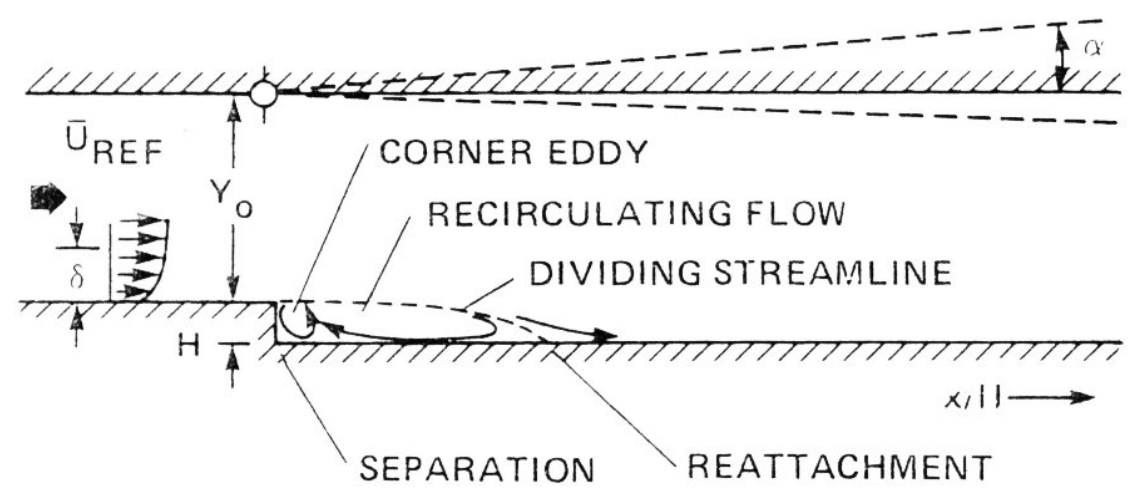

Figure 1: Schematic of Driver and Seegmiller rearward-facing step model ${ }^{13}$.

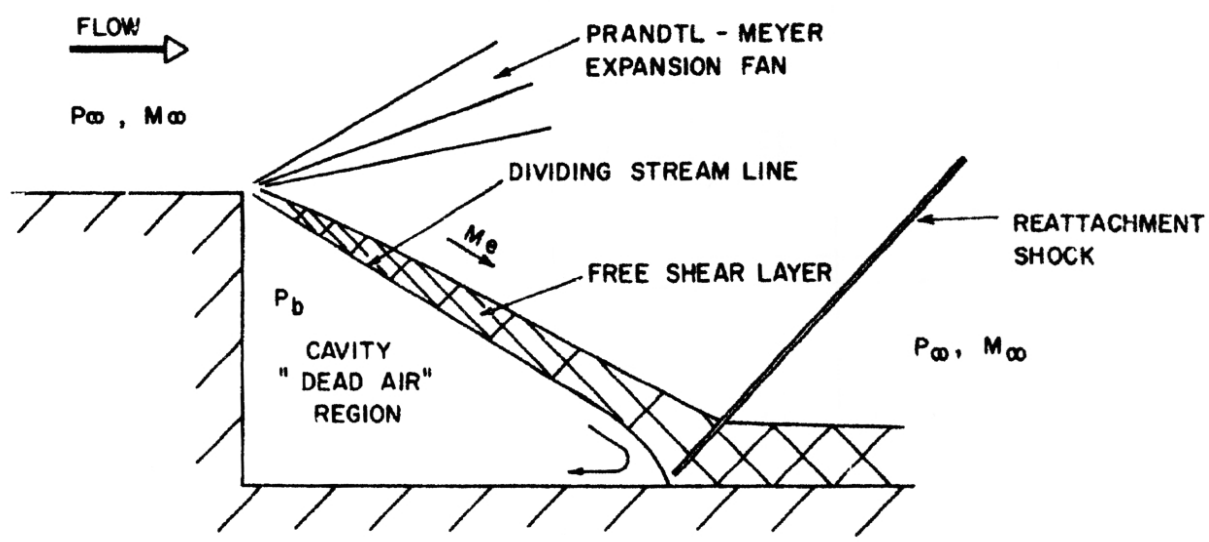

Figure 2: Chapman-Korst model supersonic flow over rearward-facing step ${ }^{14}$.

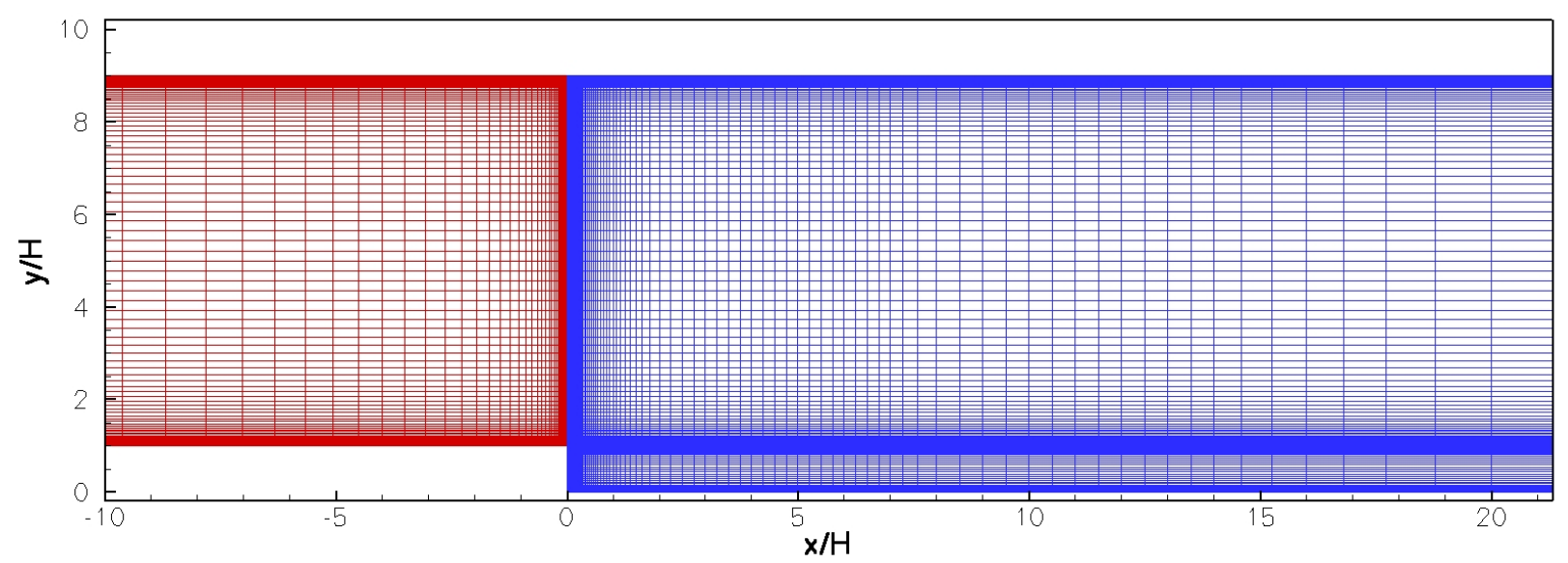

Figure 3: Two-zone grid for incompressible flow over rearward-facing step analyses. 


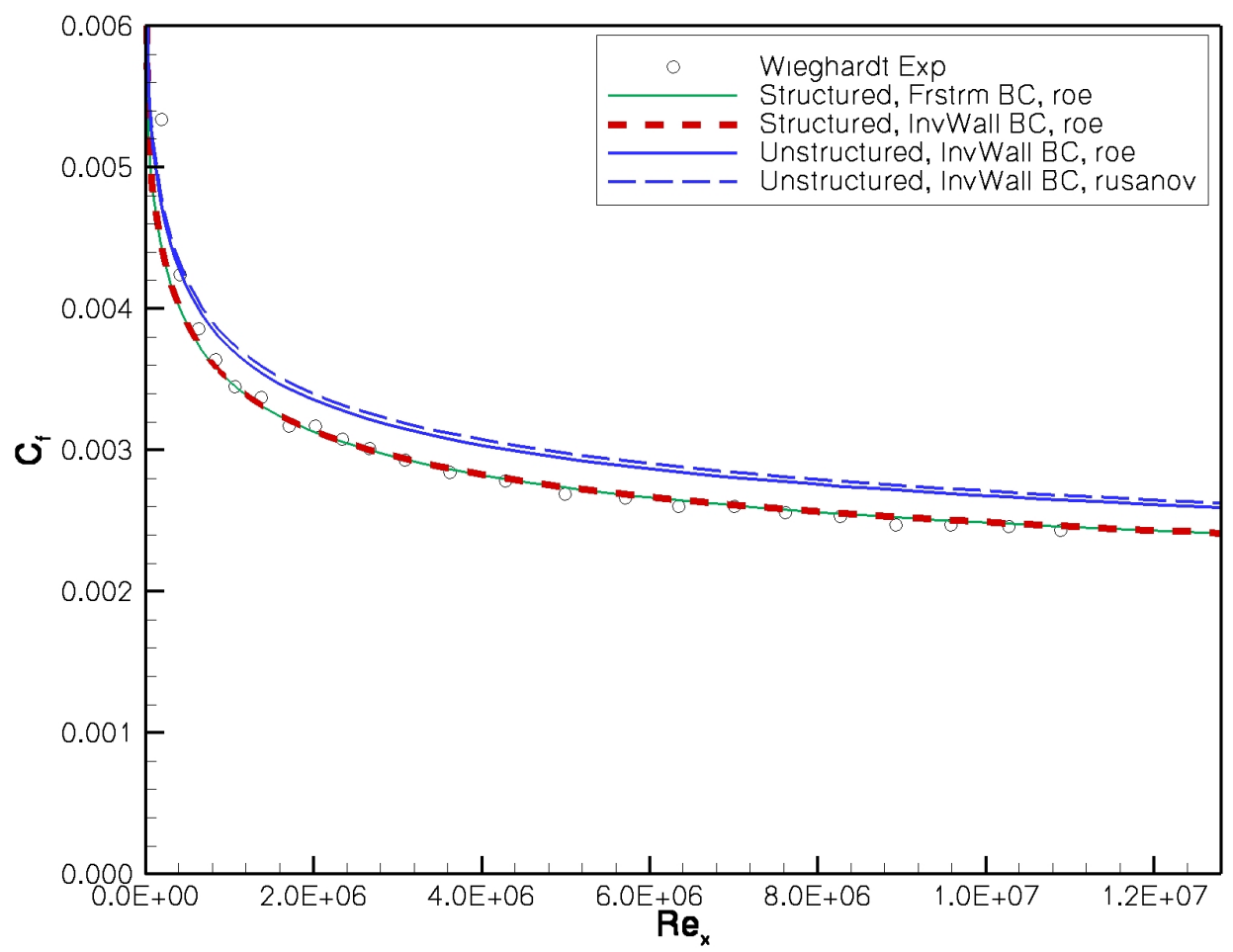

Figure 4: Incompressible flat plate skin friction plot.

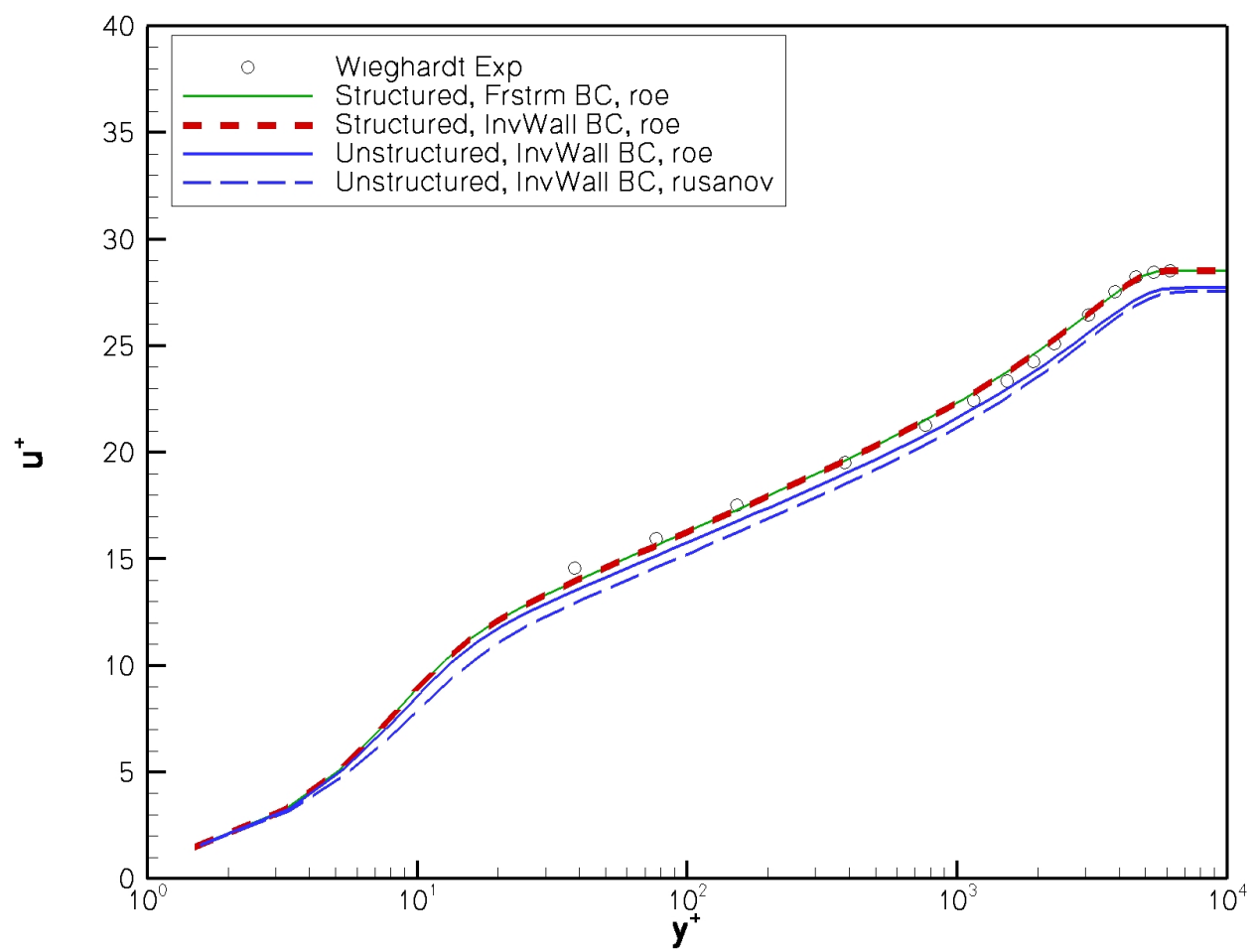

Figure 5: Incompressible flat plate velocity profile through boundary layer, $\operatorname{Re}_{x}=1.03^{*} 10^{7}$. 


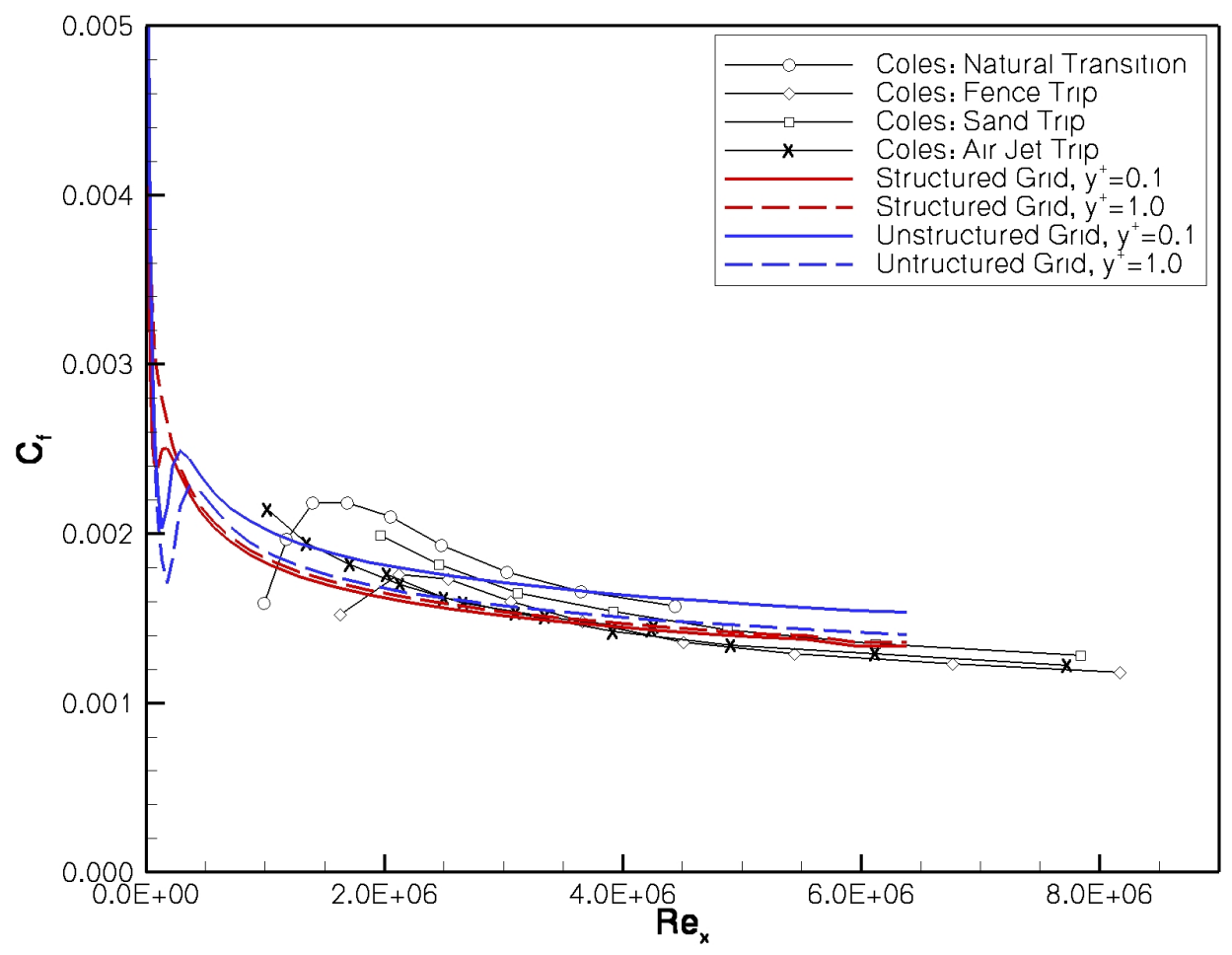

Figure 6: Supersonic flat plate skin friction plot.

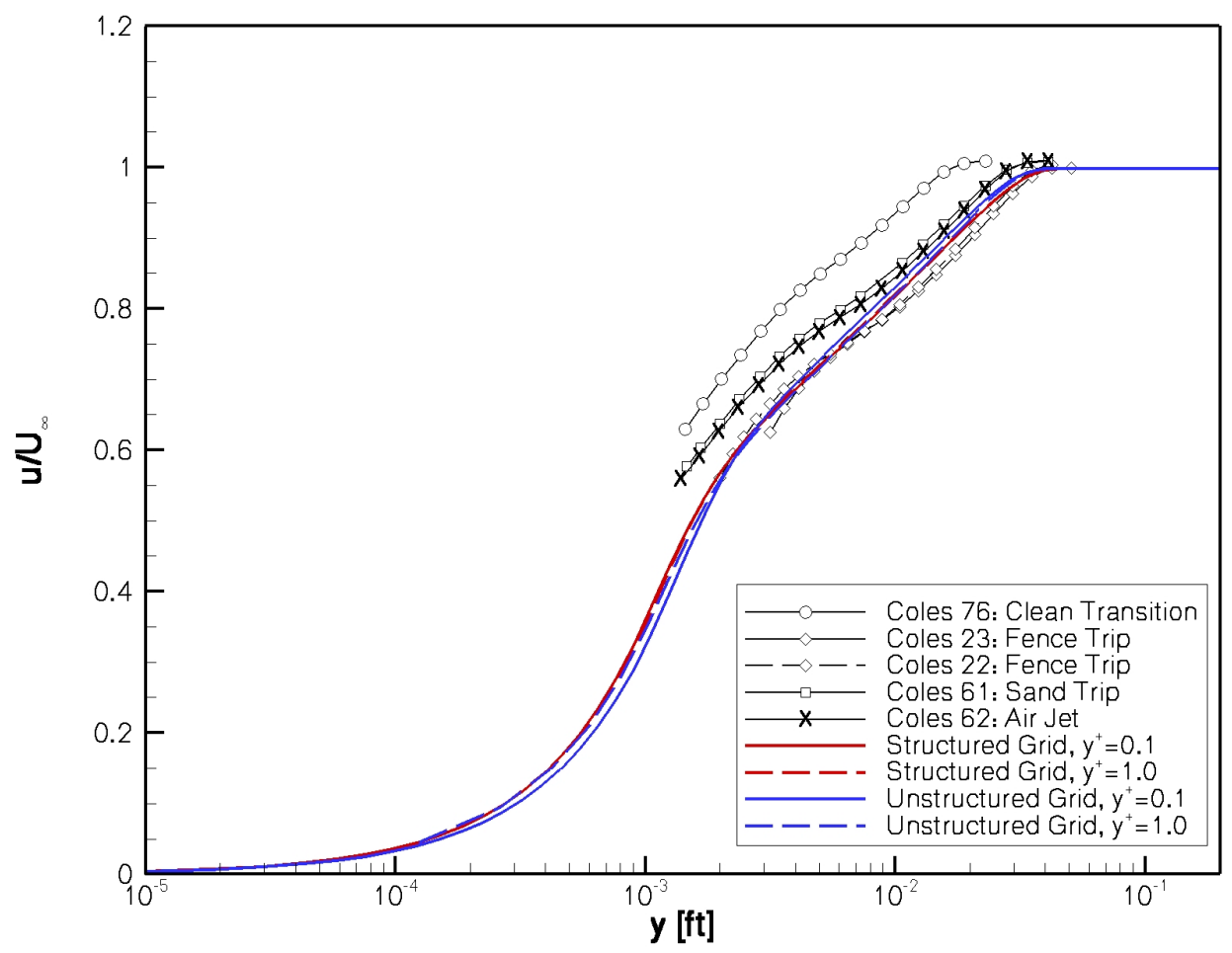

Figure 7: Supersonic flat boundary layer velocity profile, $R e_{x}=3.81^{*} 10^{6}$. 


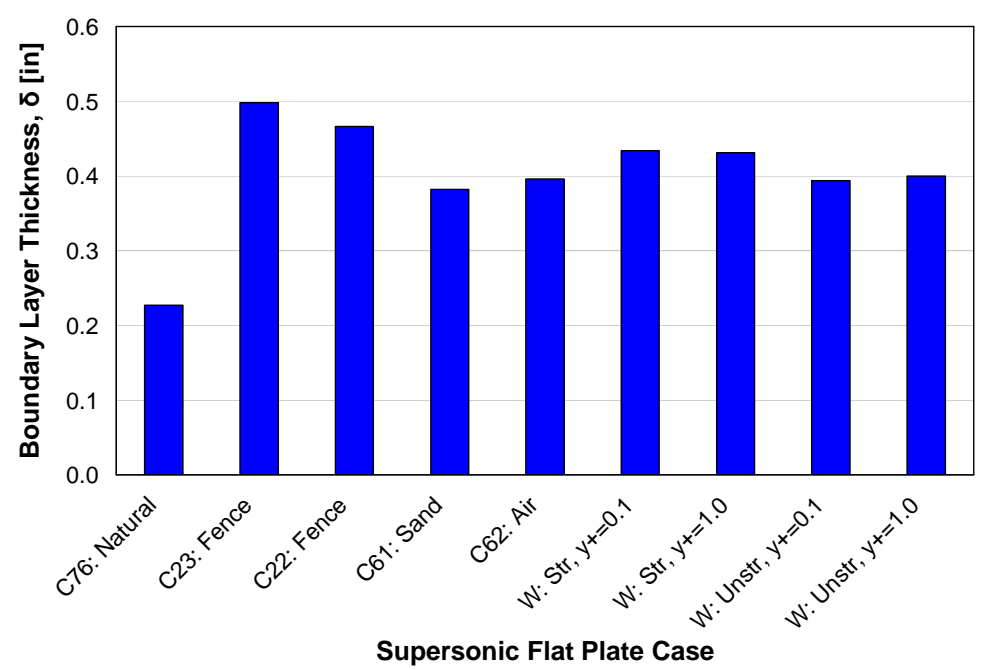

(a) Boundary layer thickness

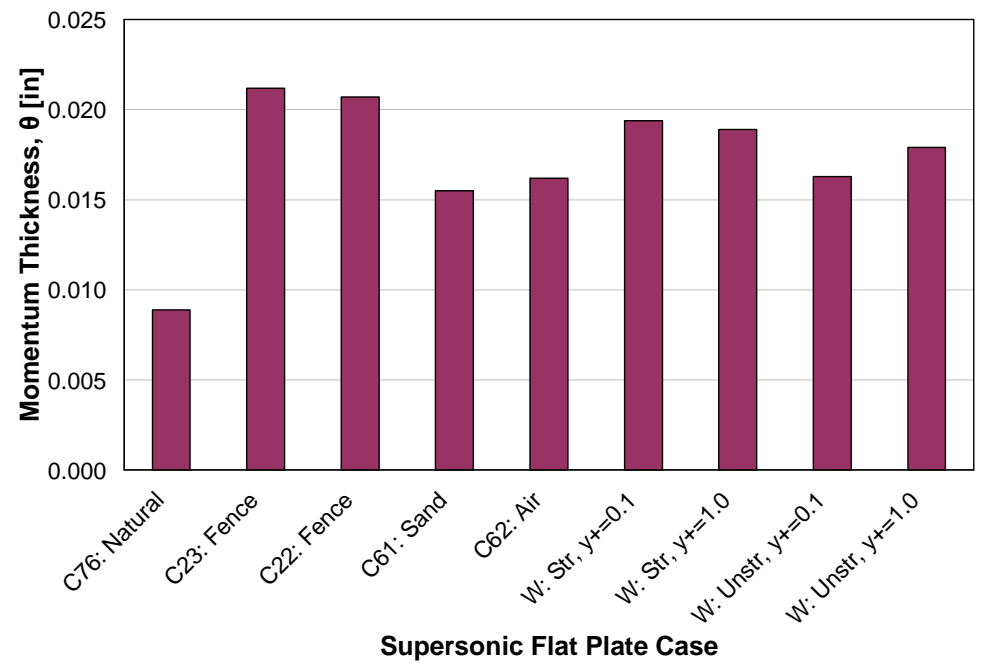

(b) Momentum thickness

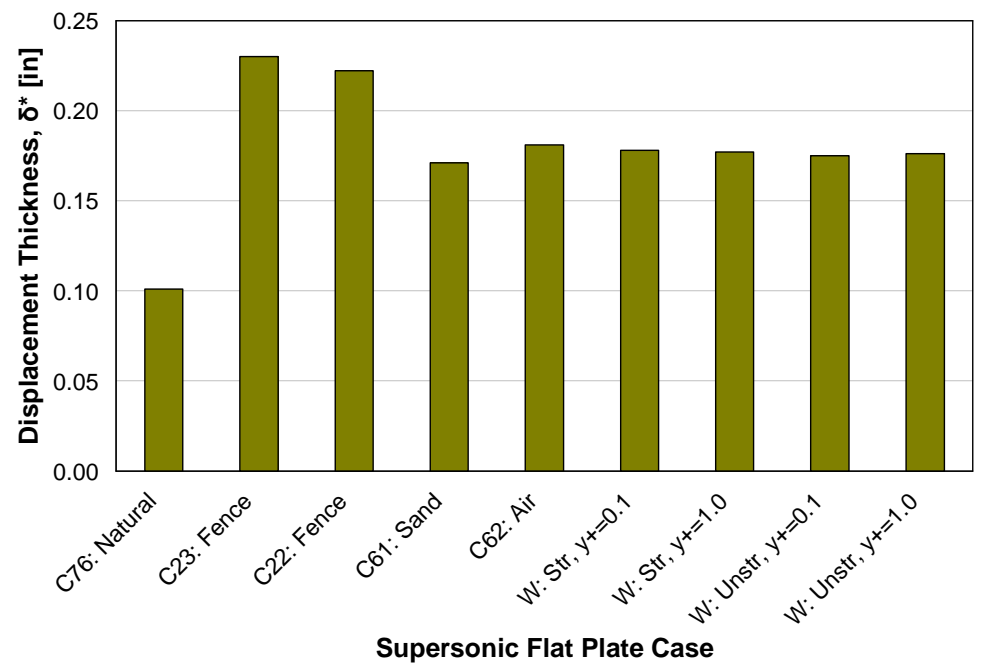

(c) Displacement thickness

Figure 8: Integrated boundary layer quantities on supersonic flat plate at $R e_{x}=3.81^{*} 10^{6}$. 


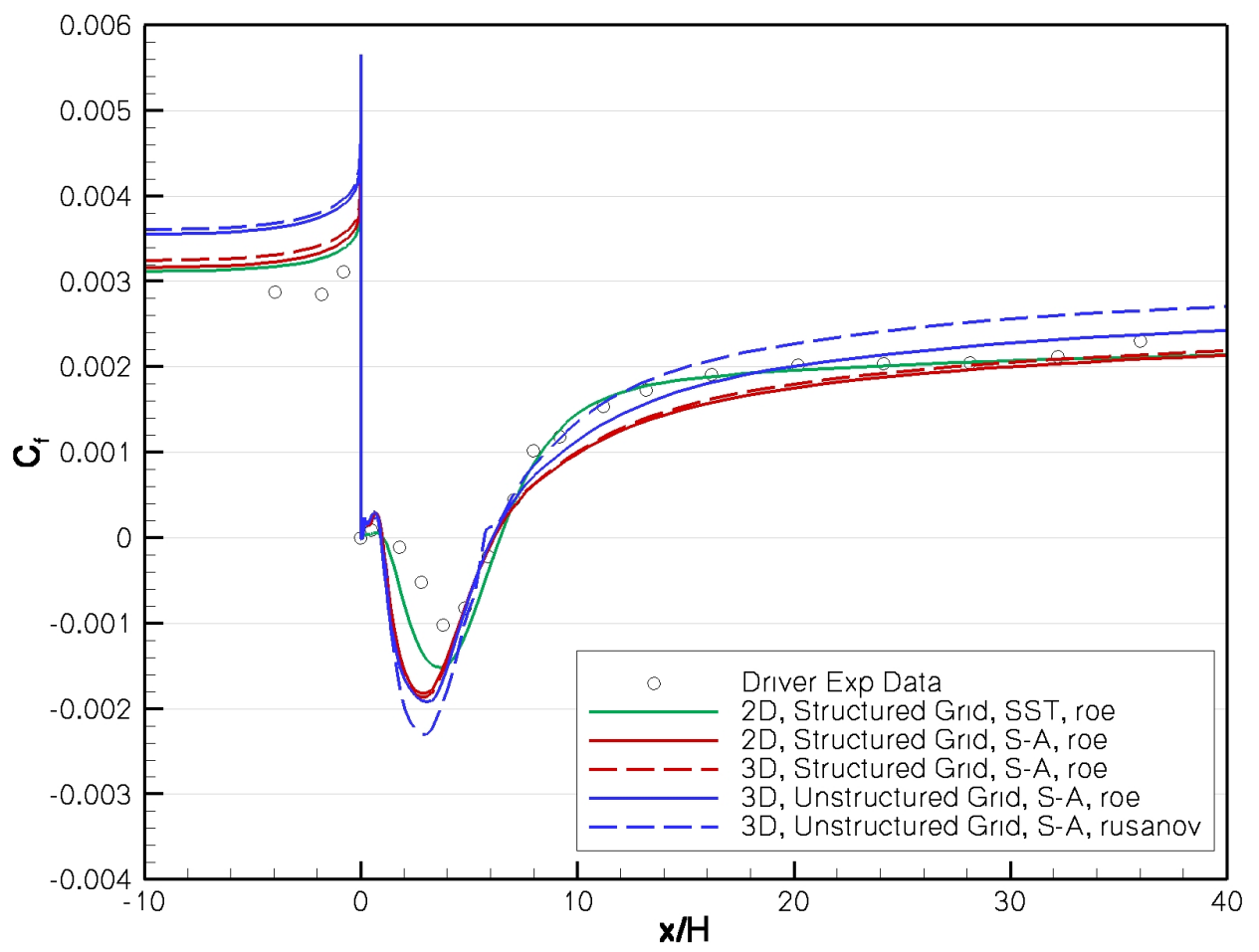

Figure 9: Incompressible rearward-facing step skin friction.

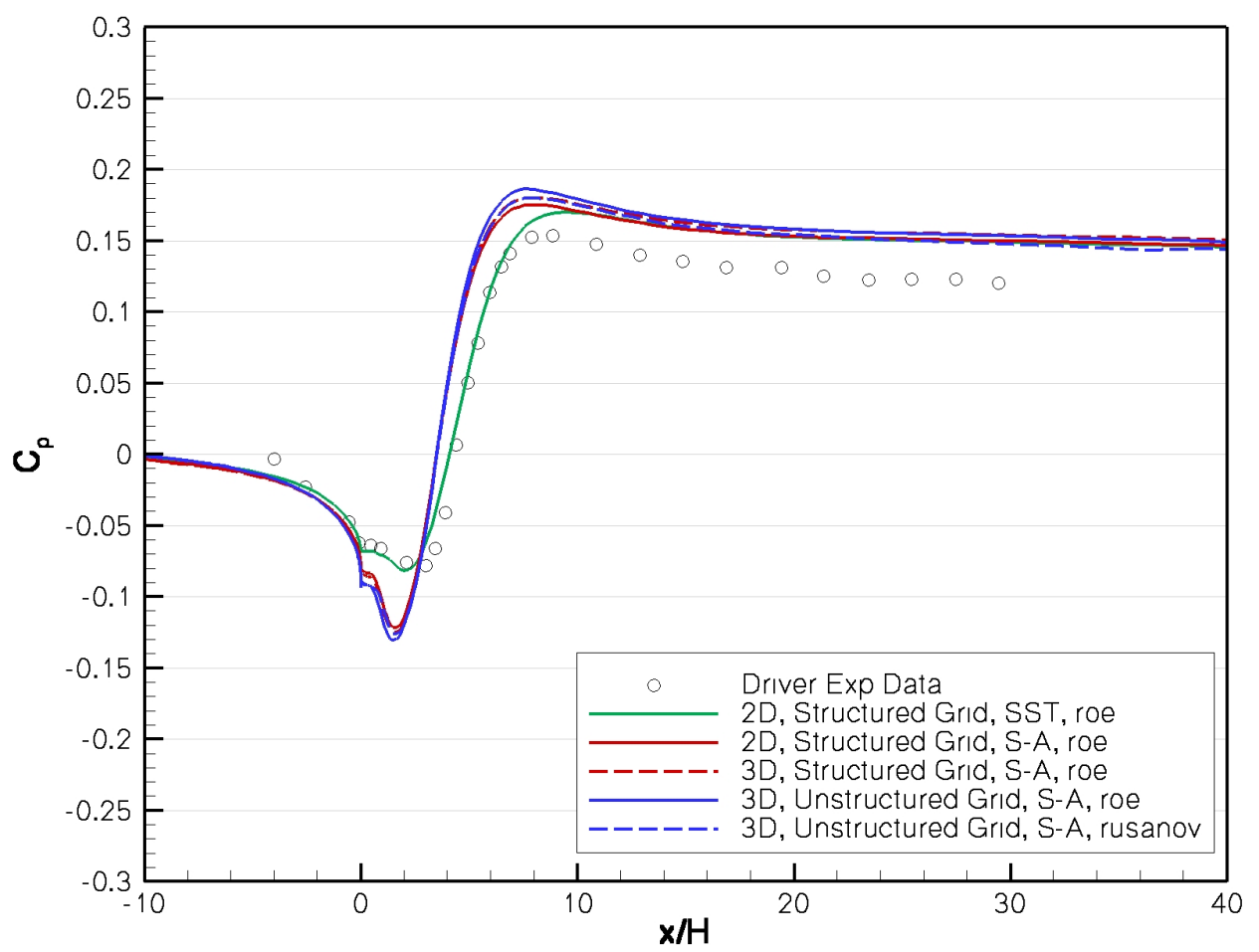

Figure 10: Incompressible rearward-facing pressure distribution. 


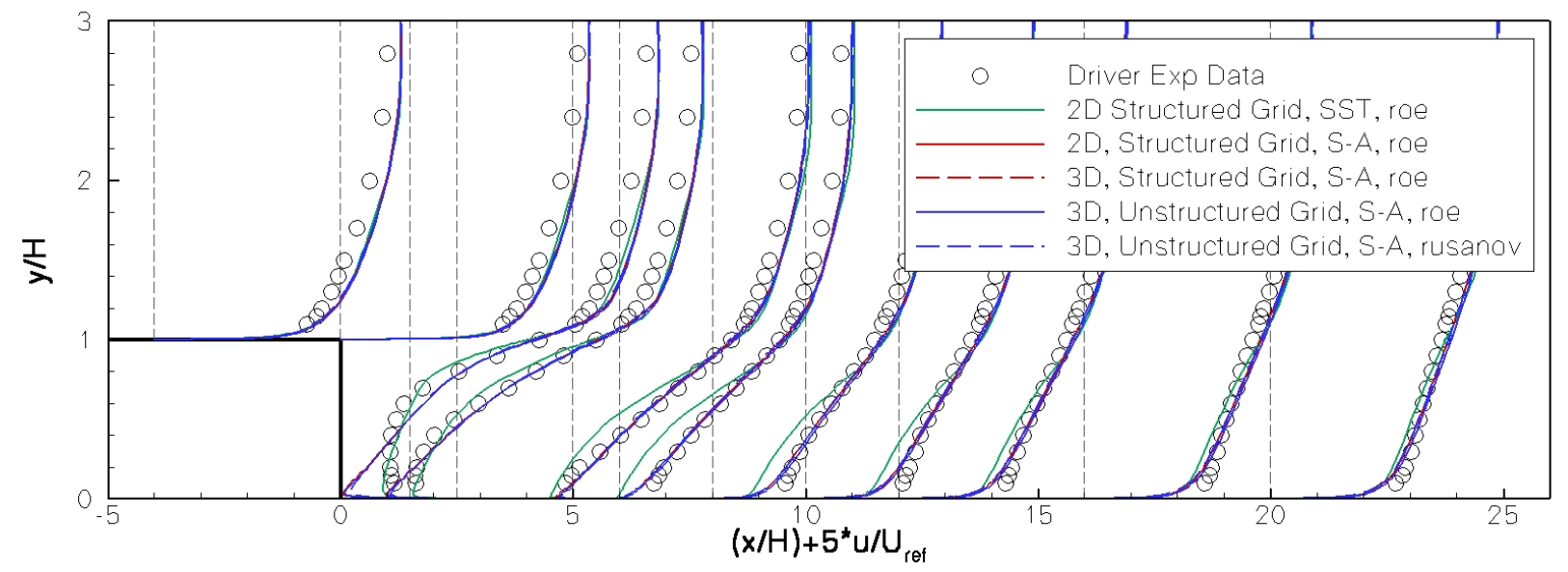

Figure 11: Incompressible rearward-facing step velocity profile.

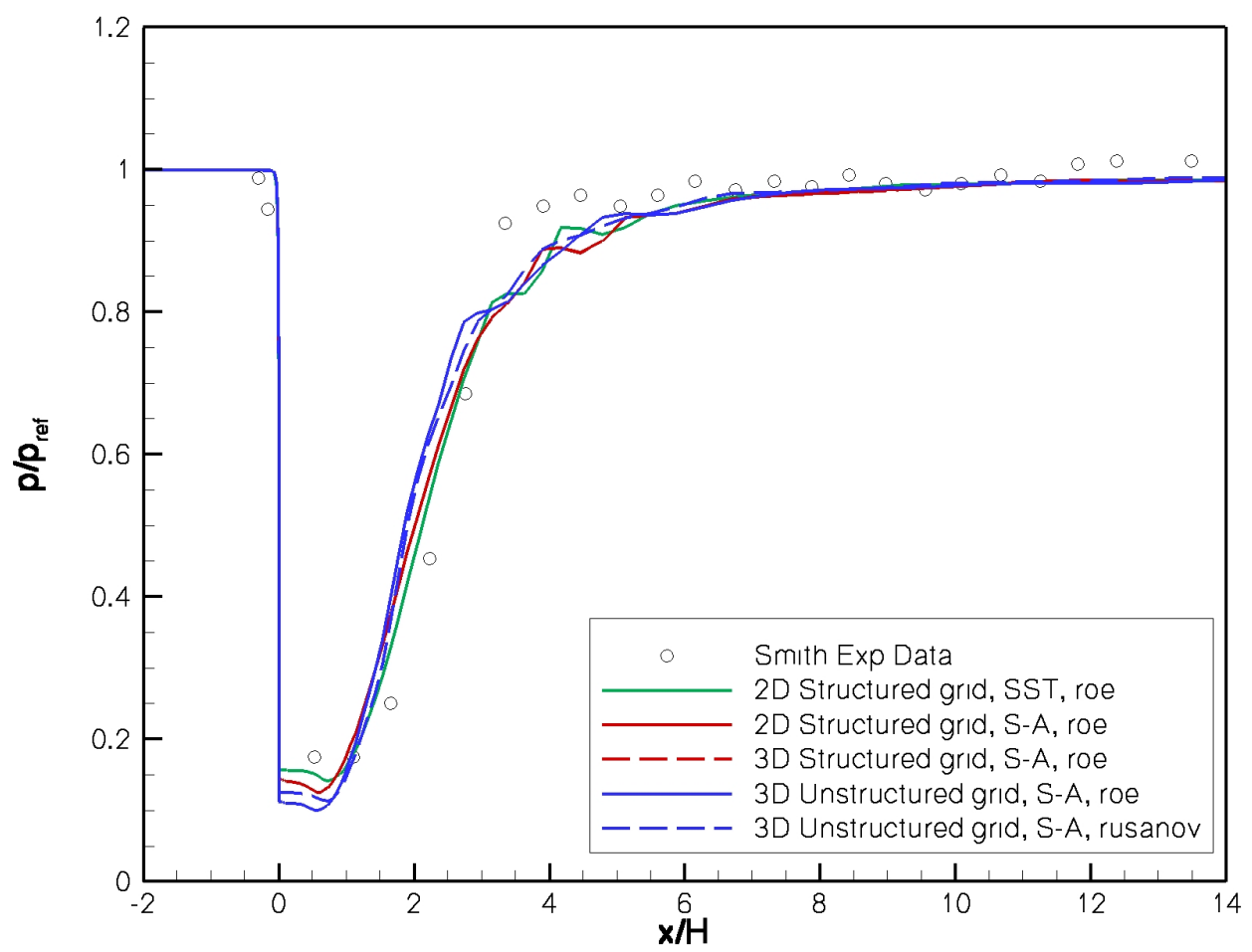

Figure 12: Pressure distribution for supersonic rearward-facing step. 


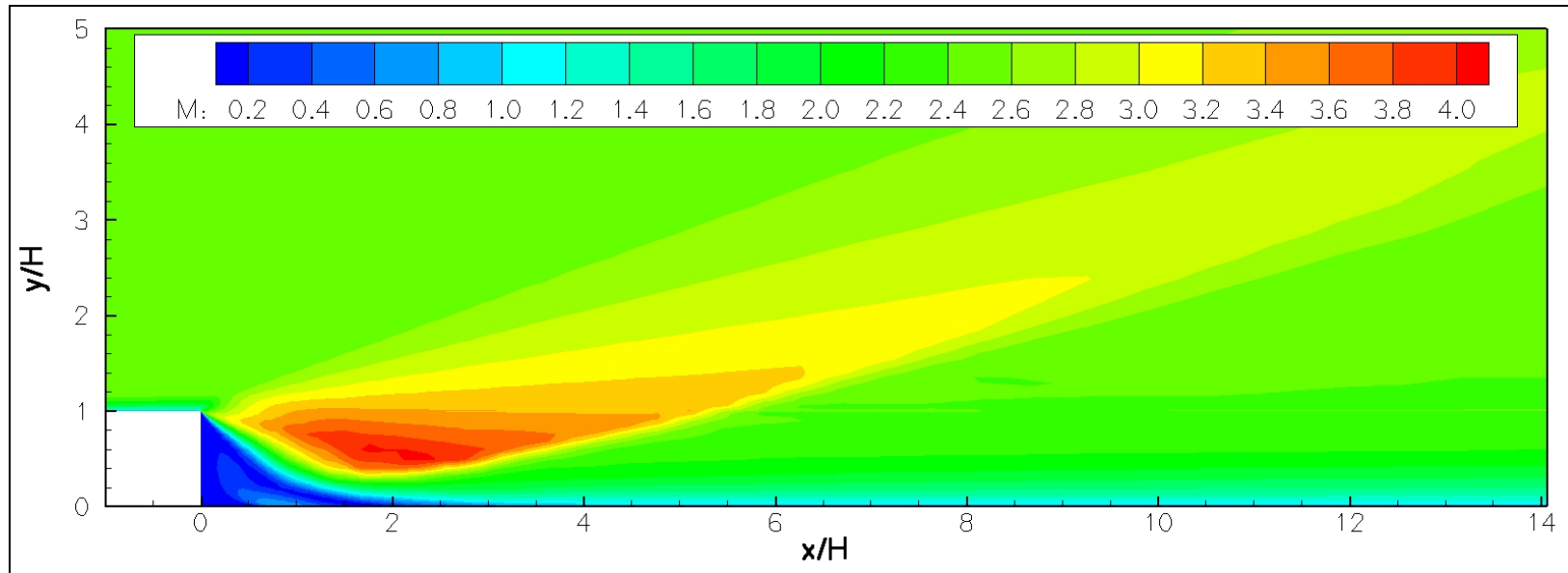

(a) Mach number contours

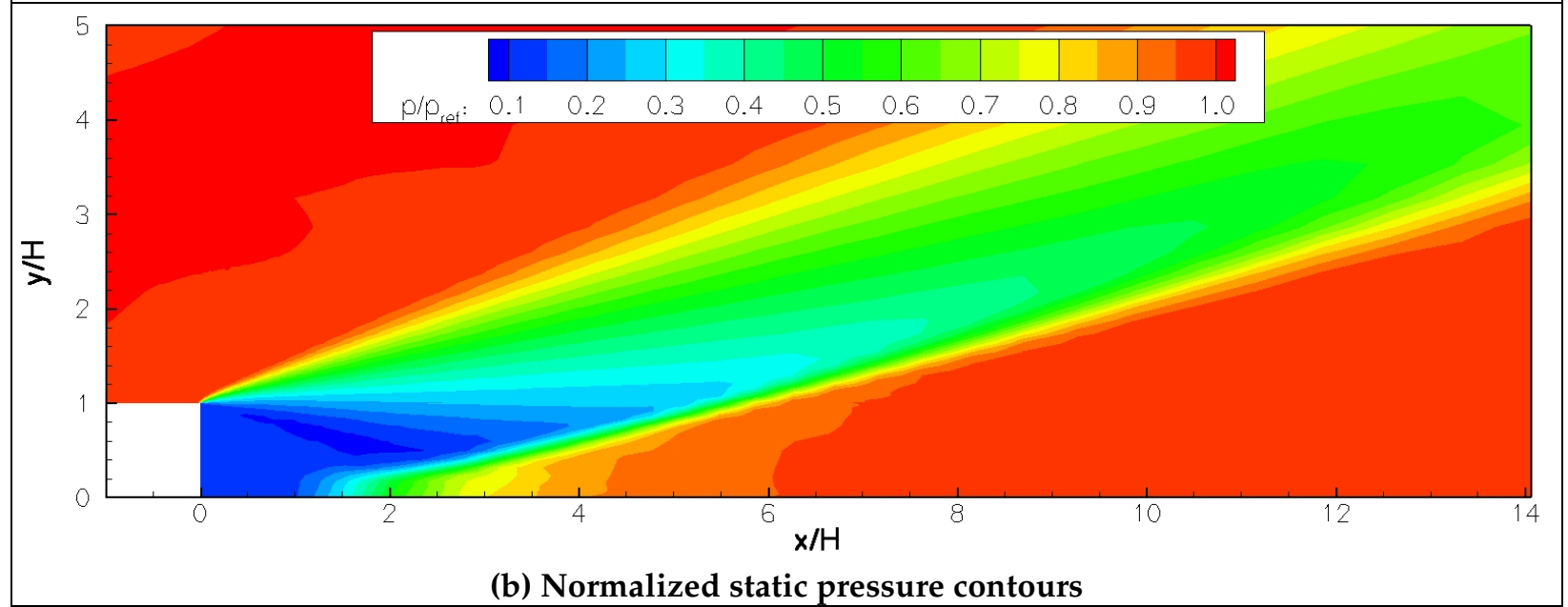

Figure 13: Flowfield contours of supersonic rearward-facing step. The solution shown used the unstructured grid with Rusanov differencing scheme. 